\title{
ПРАВОВАЯ КОММУНИКАЦИЯ
}

УДК 342, ББК 67.400, ГРНТИ 10.15., КОД ВАК 12.00 .02

О. Л. Казаниева

Барнаул, Россия

АНТИКОРРУПЦИОННАЯ

ЭКСПЕРТИЗА

МУНИЦИПАЛЬНЫХ

НОРМАТИВНЫХ ПРАВОВЫХ АКТОВ: СОСТОЯНИЕ И ПОИСК ОПТИМАЛЬНЫХ РЕШЕНИЙ

Статья посвящена анализу современного состояния института антикоррупциооной экспертизы муниципальных правовых актов и их проектов в Российской Федерации. Антикоррупщионная экспертиза является одним из направлений государственной антикоррупционной политики. В России за достаточно короткий срок сформирована правовая основа для проведения антикоррупиионной экспертизы, однако имеются некоторые недостатки в правовом регулировании антикоррупџионной экспертизы муниципальных нормативных правовых актов и их проектов, что порождает проблемы при ее осуществлении. К сожалению, следует признать, что законодатель не уделяет должного внимания вопросам противодействия коррупции на муниципальном уровне. Базовый Федеральный закон от 6 октября 2003 года № 131-Ф3 «Об общиих принциипах организаџиии местного самоуправления в Российской Федерации» содержит лишь небольшое количество норм, регламентирующих антикоррупщионную деятельность, и только в части вопросов местного значения всех типов муниципальных образований. Правовые и организационные основы антикоррупциионной экспертизы нормативных правовых актов и проектов нормативных правовых актов в целях выявления в них коррупщиогенных факторов и их последующего устранения содержатся в Федеральном законе от 3 июля 2009 года № 172-Ф3 «Об антикоррупщионной экспертизе нормативных правовых актов и проектов нормативных правовых актов», применение норм которого вызывает больше вопросов, нежели ответов. Так, например, возникает вопрос о правомочности органов государственной власти субъектов РФ проводить антикоррупщионную экспертизу мунищипальных нормативных правовых актов, поскольку в качестве субъектов ее проведения они в законе не называются.

В результате анализа действующей правовой базы и правоприменительной практики 
автор выявляет имеющииеся недостатки в институте антикорруционной экспертизы, выявляет их основные причины и предлагает пути их решения.

Ключевые слова: антикоррупционная экспертиза, муниципальный правовой акт, юридическая техника, коррупцฺиогенные факторы, антикоррупц̧ионная политика.

Сведения об авторе: Олеся Леонидовна Казанцева, кандидат юридических наук, доиеент кафедры конституичионного и международного права Алтайского государственного университета, независимый эксперт по проведению антикоррупц̧ионных экспертиз. 656049, Барнаул, пр-т Социалистический, 68, каб.412.E-mail: verwaltung@mail.ru

\section{O. L. Kazantseva}

Barnaul, Russia

ANTI-CORRUPTION EXPERTISE OF MUNICIPAL REGULATORY LEGAL ACTS: STATUS AND SEARCH OF OPTIMAL SOLUTIONS

The article is devoted to the analysis of the current state of the institution of anti-corruption expertise of municipal legal acts and their drafts in the Russian Federation. Anti-corruption expertise is one of the strands of the state anti-corruption policy. A legal basis for conducting anti-corruption expertise has been formed in Russia within a relatively short period of time, however there are some shortcomings in the legal regulation of anti-corruption expertise of municipal regulatory legal acts and their drafts, which causes problems in its implementation. Unfortunately, it should be recognized that the legislator does not pay due attention to the issues of combating corruption at the municipal level. The Basic Federal Law of October 6, 2003 No 131-FZ «On the General Principles of the Organization of Local Government in the Russian Federation» contains only a small number of rules regulating anti-corruption activities and only regarding the issues of local importance in of all types of municipalities. The Federal Law of July 3, 2009 No 172- FZ «On anti-corruption expertise of regulatory legal acts and draft regulatory legal acts» contains legal and organizational bases of anticorruption expertise of normative legal acts and draft normative legal acts in order to identify corruption-related factors and their subsequent elimination, The implementation of the norms of the given law raises more questions than answers. Thus, for example, a question arises if authorities of the constituent entities of the Russian Federation have legal power to conduct anti-corruption expertise of municipal regulatory legal acts, since the law doesn't mention them as its subjects.

As a result of the analysis of the existing legal framework and law enforcement practice, the author identifies the shortcomings existing in the institute of anti-corruption expertise, identifies their main causes and suggests ways to solve them.

Key words: anti-corruption expertise, municipal legal act, legal technique, corruption-related factors, anti-corruption policy. 
About the author: Olesya Leonidovna Kazantseva, Candidate of Law, Associate Professor of the Chair of Constitutional and International Law, Altai State University. 656049, Barnaul, Prospect Sotsialisticheskiy, 68, office 412.E-mail:verwaltung@mail.ru

Муниципальное нормотворчество представляет собой одно из основных направлений деятельности органов местного самоуправления. Результатом муниципального нормотворчества является муниципальный правовой акт.

Под муниципальным правовым актом понимается «решение, принятое непосредственно населением муниципального образования по вопросам местного значения, либо решение, принятое органом местного самоуправления и (или) должностным лицом местного самоуправления по вопросам местного значения, по вопросам осуществления отдельных государственных полномочий, переданных органам местного самоуправления федеральными законами и законами субъектов Российской Федерации, а также по иным вопросам, отнесенным уставом муниципального образования в соответствии с федеральными законами к полномочиям органов местного самоуправления и (или) должностных лиц местного самоуправления, документально оформленные, обязательные для исполнения на территории муниципального образования, устанавливающие либо изменяющие общеобязательные правила или имеющие индивидуальный характер» (ст. 2 Федерального закона от 6 октября 2003 года № 131-Ф3 «Об общих принципах организации местного самоуправления в Российской Федерации» (далее - Ф3 № 131)).

Муниципальные правовые акты могут носить нормативный и ненормативный характер. В большей степени в рамках настоящей статьи интерес представляют нормативные правовые акты, поскольку они рассчитаны на многократное применение и распространяют свое действие на неопределенный круг лиц, а следовательно, затрагивают права и свободы широкого круга граждан. Кроме того, только в отношении нормативных правовых актов может проводиться антикоррупционная экспертиза в соответствии с Федеральным законом от 3 июля 2009 года № 172-Ф3 «Об антикоррупционной экспертизе нормативных правовых актов и проектов нормативных правовых актов» (далее - Ф3 № 172). 
Поскольку законодательно понятие нормативного правового акта не установлено, следует руководствоваться п. 9 Постановления Пленума Верховного Суда Российской Федерации от 29 ноября 2007 года № 48 «О практике рассмотрения судами дел об оспаривании нормативных правовых актов полностью или в части», где закреплены существенные признаки нормативного правового акта: 1) издание его в установленном порядке, 2) издание его управомоченным органом государственной власти, органом местного самоуправления или должностным лицом, 3) наличие в нем правовых норм (правил поведения), обязательных для неопределенного круга лиц, 4) указанные правила поведения рассчитаны на неоднократное применение, 5) указанные правила поведения направлены на урегулирование общественных отношений либо на изменение или прекращение существующих правоотношений.

Несмотря на имеющиеся критерии нормативности, названные в вышеуказанном Постановлении Пленума Верховного Суда Российской Федерации, на практике при определении нормативности муниципальных правовых актов все-таки возникают разногласия между правотворческими органами местного самоуправления и органами прокуратуры, органами юстиции, органами государственной власти субъектов РФ.

Качество муниципальных правовых актов является острейшей проблемой [Аблиев 2017: 124; Казанцева 2013: 72]. Как показывает практика, именно на уровне местного самоуправления допускается наибольшее количество дефектных норм. При этом низкое качество муниципальных актов характерно преимущественно для сельских поселений. Это обусловлено объективными причинами, а именно отсутствием средств в местном бюджете для формирования кадрового состава органов местного самоуправления лицами, имеющими юридическое образование. Многие исследователи поднимают эту проблему в своих научных трудах [Дымберова 2014: 63; Николаева, Паулов 2018: 278]. Так, например, В. И. Васильев справедливо отмечает: «При определении арсенала антикоррупционных средств, предусматриваемых национальными программами борьбы с коррупцией, должны реально учитываться возможности муниципальных 
образований, их специфика» (цит. по [Хабриева 2012: 331]). Данное утверждение абсолютно обосновано. Отсутствие юридических служб, юристов в сельских и поселковых органах местного самоуправления снижает качество и эффективность их нормотворческой деятельности.

Качество нормативных муниципальных правовых актов зависит от соблюдения требований, предъявляемых к ним. К таким требованиям относятся законность и соблюдение юридической техники. В условиях постоянно меняющегося законодательства о местном самоуправлении существенно увеличивается нагрузка органов местного самоуправления, возрастает значение качественной подготовки муниципальных правовых актов, а также соблюдения юридической техники при подготовке их проектов.

Устранить имеющиеся в нормативных правовых актах дефекты призваны правовая и антикорруционная экспертизы, которые законодатель разделяет. Так, согласно ч. 4 ст. 3 Ф3 № 172 органы, организации, их должностные лица проводят антикоррупционную экспертизу принятых ими нормативных правовых актов (проектов нормативных правовых актов) при проведении их правовой экспертизы. При этом антикоррупционная экспертиза должна осуществляться в отношении действующих правовых актов одновременно с правовой экспертизой. Исходя из анализа ч. 4 ст. 3 Ф3 № 172 можно сделать вывод о том, что законодатель разграничивает правовую и антикоррупционную экспертизы. Однако в научной литературе можно встретить различные подходы к соотношению данных экспертиз. Так, например, согласно позиции одних авторов, правовая экспертиза рассматривается в широком смысле, в нее включаются судебная, градостроительная, экологическая, криминалистическая экспертизы [Братановский, Зеленов 2012: 20]. Правовая экспертиза рассматривается как сложный, многогранный правовой феномен, включающий наряду с другими видами «антикоррупционную экспертизу». [Петренко 2011: 86]. Другие же авторы разграничивают антикоррупционную экспертизу и правовую, несмотря на их общую составляющую [Балдин 2014: 48; Родионова 2010: 161].

В соответствии со ст. 3 Ф3 № 172 антикоррупционную экспертизу 
муниципальных нормативных правовых актов (их проектов) проводят органы местного самоуправления, органы прокуратуры (в отношении нормативных правовых актов, указанных в ч. 2 ст. 3 данного Закона) и Министерство юстиции РФ (в отношении уставов муниципальных образований и муниципальных правовых актов о внесении изменений в уставы муниципальных образований при их государственной регистрации).

Анализ положений ст. 3 позволяет сделать вывод о том, что сами разработчики нормативных муниципальных правовых актов проводят антикоррупционную экспертизу в отношении ими же принятых актов. Однако результаты антикоррупционной экспертизы в отношении собственно принятых актов не всегда могут быть объективны. Вместе с тем, согласно п. 3 ст. 2 Ф3 № 172, одним из основных принципов организации антикоррупционной экспертизы нормативных правовых актов и их проектов является принцип объективности, выражающийся в максимальном абстрагировании от субъективных факторов (эмоционального восприятия информации, личной заинтересованности эксперта, иных обстоятельств) при подготовке выводов по итогам проведения антикоррупционной экспертизы.

В отличие от муниципальных правовых актов, нормативные правовые акты (их проекты) органов государственной власти подлежат помимо ведомственной экспертизы обязательной антикоррупционной экспертизе в Министерстве юстиции России. Поскольку наибольшее количество коррупциогенных факторов обнаруживается в нормативных муниципальных правовых актах, вызывает некоторое недоумение тот факт, что законодатель оставил самый уязвимый уровень власти (муниципальный) без обязательной антикоррупционной экспертизы.

В Ф3 № 172 в качестве субъектов антикоррупционной экспертизы муниципальных нормативных правовых актов отсутствуют органы государственной власти субъектов РФ. Однако, в соответствии с некоторыми региональными актами о порядке ведения регистра муниципальных правовых актов, наряду с правовой экспертизой зачастую предусматривалось 
осуществление антикоррупционной экспертизы.

К примеру, в Алтайском крае был принят Закон от 3 декабря 2008 года № 122-3С «О Регистре муниципальных нормативных правовых актов Алтайского края», согласно подп. 4 п. 4 ст. 4 которого при ведении регистра в порядке, установленном федеральным законодательством и законодательством Алтайского края, осуществлялись правовая и антикоррупционная экспертиза муниципальных нормативных правовых актов в порядке, устанавливаемом Губернатором Алтайского края, и направление в принявший их орган местного самоуправления (должностному лицу местного самоуправления) сведений о выявленных положениях, противоречащих Конституции Российской Федерации, федеральному законодательству, законодательству Алтайского края, уставу муниципального образования, а также о коррупциогенных факторах.

С одной стороны, закрепление такого положения в региональных актах, в частности в Законе Алтайского края от 3 декабря 2008 года № 122-3С, входило в противоречие с нормами Ф3 № 172, который не предусматривает такого субъекта антикоррупционной экспертизы муниципальных правовых актов как органы государственной власти субъектов РФ. С другой стороны, проведение антикоррупционной экспертизы является объективной необходимостью.

В соответствии с подп. 64 п. 2 ст. 26.3 Федерального закона от 6 октября 1999 года № 184-Ф3 «Об общих принципах организации законодательных (представительных) и исполнительных органов государственной власти субъектов Российской Федерации» к полномочиям органов государственной власти субъекта РФ отнесено решение вопросов организации и ведения регистра муниципальных нормативных правовых актов. Согласно п. 2. Положения о ведении федерального регистра муниципальных нормативных правовых актов, утвержденного постановлением Правительства РФ от 10 сентября 2008 года № 657, регистр ведется в целях обеспечения верховенства Конституции Российской Федерации и федеральных законов, а следовательно, муниципальные правовые акты должны подвергаться правовой экспертизе.

В настоящее время действует Закон Алтайского края от 4 июля 2017 года 
№ 46-3С «О регистре муниципальных нормативных правовых актов Алтайского края», согласно подп. 4 п. 3 ст. 5 которого ведение регистра включает в себя проведение правовой экспертизы муниципальных правовых актов, что соответствует ФЗ № 172.

В Алтайском крае уполномоченным органом на ведение регистра муниципальных правовых актов являлось Министерство юстиции Алтайского края. Подп. 6 п. 2.1.1. Положения о Министерстве юстиции Алтайского края, утвержденного Указом Губернатора Алтайского края от 24.11.2016 № 145, закреплял, что Министерство юстиции в сфере обеспечения законности нормативного правового регулирования проводит правовую экспертизу муниципальных нормативных правовых актов, подлежащих включению в регистр муниципальных нормативных правовых актов Алтайского края. В настоящее время в соответствии с Указом Губернатора Алтайского края от 16 октября 2018 года № 156 в структуре органов исполнительной власти Алтайского края образовано Управление юстиции, выполняющее полномочия ранее созданного Министерства юстиции Алтайского края.

Правовые и организационные основы антикоррупционной экспертизы содержатся в Ф3 № 172. Методика проведения антикоррупционной экспертизы утверждена Постановлением Правительства РФ от 26 февраля 2010 года № 96, в котором выделяются виды коррупциогенных факторов: положения, которые устанавливают для правоприменителя необоснованно широкие пределы усмотрения или возможность необоснованного применения исключений из общих правил; положения, которые содержат неопределенные, трудновыполнимые, обременительные требования к гражданам и организациям, что создает условия для проявления коррупции.

Поскольку коррупциогенные факторы методикой не раскрываются, а только называются, на практике вызывает затруднение выявление их в нормативных правовых актах и их проектах.

Наиболее распространены следующие коррупциогенные факторы, выявляемые в муниципальных правовых актах: широта дискреционных 
полномочий, выраженная в отсутствии сроков или их неопределенности, отсутствии условий принятия решения, отсутствии оснований; дублирующие полномочия органов местного самоуправления; принятие нормативного правового акта за пределами компетенции, а именно нарушение компетенции органов местного самоуправления при принятии нормативных правовых актов; заполнение законодательных пробелов при помощи подзаконных актов в отсутствие законодательной делегации соответствующих полномочий; отсутствие или неполнота административных процедур, необходимых для обеспечения интересов жителей муниципального образования; отказ от конкурсных (аукционных) процедур; наличие завышенных требований к лицу, предъявляемых для реализации принадлежащего ему права; юридиколингвистическая неопределенность - употребление не устоявшихся, двусмысленных терминов и категорий оценочного характера.

Проведение антикоррупционной экспертизы муниципальных правовых актов уже дает положительные результаты, снижая коррупциогенность принимаемых нормативных правовых актов [Муртазина 2010: 159]. В целях совершенствования института антикоррупционной экспертизы муниципальных правовых актов, выявления на ранней стадии правотворческого процесса коррупциогенных факторов в проектах муниципальных правовых актов необходимо систематически повышать правовую грамотность депутатов представительных органов местного самоуправления, муниципальных служащих органов местного самоуправления путем проведения систематических учеб, направленных на разъяснение действующего законодательства, изучение юридической терминологии и правил юридической техники. Таким образом, необходима оптимизация всей правотворческой деятельности органов местного самоуправления, и проводить ее надо совместными усилиями всех уровней публичной власти.

\section{ЛИТЕРАТУРА}

1. Аблиев T. M. Tеоретические $\quad$ проблемы $\quad$ антикоррупционной $\quad$ экспертизы муниципальных нормативных правовых актов и проектов муниципальных нормативных 
правовых актов. Теория и практика общественного развития. 2017. № 6. С. 123-130.

2. Балдин A. K. Антикоррупционная экспертиза нормативных правовых актов как инструмент познания правовой материи в системе юридических экспертиз. Современное право. 2014. № 2. С. 46-49.

3. Братановский С. Н., Зеленов М. Ф. Сущность антикоррупционной экспертизы как вида правовой экспертизы. Вестник Сибирской академии права, экономики и управления. 2012. № 1 (5). С. 20-23.

4. Дымберова Э. Д. Антикоррупционная экспертиза муниципальных нормативных правовых актов: состояние и поиск путей совершенствования. Журнал российского права. 2014. № 9 (213). С. 62-68.

5. Казанцева О. Л. Проблемы правотворческой деятельности муниципальных образований в Российской Федерации. Вестник Новосибирского государственного университета. Серия «Право». 2013. Т. 9. № 2. С. 69-74.

6. Коррупция: природа, проявления, противодействие. М., 2012.

7. Муртазина Г. М. Антикоррупционная экспертиза муниципальных нормативных правовых актов как мера борьбы с коррупцией. Актуальные проблемы экономики и права. 2010. № 1 (13). С. 155-160.

8. Николаева Д. В., Паулов П. А. Проблемы нормотворчества органов местного самоуправления. Современные научные исследования и разработки. 2018. № 1 (18). С. $277-$ 279.

9. Петренко А. В. Антикоррупционная экспертиза в Российской Федерации как вид правовой экспертизы. Наука и образование: хозяйство и экономика; предпринимательство; право и управление. 2011. № 2 (8). С. 85-87.

10. Родионова O.Н. Антикоррупционная экспертиза. Российский юридический журнал. 2010. № 1. С. 158-162.

\section{REFERENCES}

1. Abliyev T. M. Theoretical problems of anti-corruption expertise of municipal normative legal acts and projects of municipal normative legal acts [Teoreticheskiye problemy antikorruptsionnoy ekspertizy munitsipal'nykh normativnykh pravovykh aktov i proyektov munitsipal'nykh normativnykh pravovykh aktov]. Theory and practice of social development. 2017. № 6. Pp. $123-130$.

2. Baldin A. K. Anti-corruption expertise of normative legal acts as an instrument of knowledge of legal matter in the system of legal examinations [Antikorruptsionnaya ekspertiza normativnykh pravovykh aktov kak instrument]. Modern law. 2014. № 2. Pp. 46-49. 
3. Bratanovskiy S. N., Zelenov M. F. Essence of anti-corruption expertise as a type of legal expertise [Sushchnost' antikorruptsionnoy ekspertizy kak vid pravovoy ekspertizy]. Bulletin of the Siberian Academy of Law, Economics and Management. 2012. № 1 (5). Pp. 20-23.

4. Dymberova E. D. Anti-corruption expertise of municipal regulatory legal acts: status and search for ways to improve [Antikorruptsionnaya ekspertiza munitsipal'nykh normativnykh pravovykh aktov: sostoyaniye i poisk putey sovershenstvovaniya]. Journal of Russian Law. 2014. № 9 (213). Pp. 62-68.

5. Kazantseva O. L. Problems of law-making activities of municipalities in the Russian Federation [Problemy pravotvorcheskoy deyatel'nosti munitsipal'nykh obrazovaniy v Rossiyskoy Federatsii]. Bulletin of the Novosibirsk State University. Series «Law». 2013. T. 9. № 2. Pp. 69-74.

6. Corruption: nature, manifestations, opposition [Korruptsiya: priroda, proyavleniya, protivodeystviye]. Moscow, 2012.

7. Murtazina G. M. Anti-corruption expertise of municipal regulatory legal acts as a measure to combat corruption [Antikorruptsionnaya ekspertiza munitsipal'nykh normativnykh pravovykh aktov kak mera bor'by s korruptsiyey]. Actual problems of economics and law. 2010. № 1 (13). Pp. 155-160.

8. Nikolayeva D. V., Paulov P. A. Problems of the rule-making bodies of local governments [Problemy normotvorchestva organov mestnogo samoupravleniya]. Modern research and development. 2018. № 1 (18). Pp. 277-279.

9. Petrenko A. V. Anti-corruption expertise in the Russian Federation as a type of legal expertise [Antikorruptsionnaya ekspertiza v Rossiyskoy Federatsii kak vid pravovoy ekspertizy]. Science and education: economy and economy; entrepreneurship; law and administration. 2011. № 2 (8). Pp. 85-87.

10. Rodionova O. N. Anti-corruption expertise [Antikorruptsionnaya ekspertiza]. Russian legal journal. 2010. № 1. Pp. 158-162. 